\title{
Peculiarities of interest rates as forecasting indicator in Russian economy
}

\author{
Grigorieva Elena Mikhailovna \\ Department of Finance and Credit \\ PEOPLES' FRIENDSHIP UNIVERSITY OF RUSSIA \\ Moscow Russia \\ Grigoryeva_Elena@ rudn.university
}

\author{
Valkov Dmitry Sergeevich \\ Department of Finance and Credit \\ PEOPLES' FRIENDSHIP UNIVERSITY OF RUSSIA \\ Moscow Russia \\ dm.valkov91@gmail.com
}

\begin{abstract}
The article studies the dynamics of different macroeconomic indicators from the point of view of their forecasting ability in the Russian economy in the period of 20122016. The article considers the changes in such macro-indicators as benchmark interest rates, the curve of zero-coupon yield, government stock rates spread and inflation-adjusted money supply. In so doing, the article compares these indicators with their American analogues. The main point was to study the way the indicators were changing, the accuracy of their reflecting the economic situation and whether they should be applied to the Russian economy on the basis of foreign experience (for example, the "Index of Leading Indicators" published by the Conference Board). This issue has been in the focus of Russian and foreign authors as they try to construct the system of economic forecasting. The revealing of these forecasting instruments is a difficult process allowing for the significant number of various indicators and differing market conditions. As a result of the study, the authors uncovered that some of the proposed indicators reflect basic changes in economy as well they have significant forecasting abilities and can be 1-2 quarters ahead of the general situation on the market.
\end{abstract}

Keywords - benchmark interest rate, bonds rates, curve of zerocoupon yield, M3 Money aggregate

\section{INTEREST RATES AND MONEY SUPPLY AS INDICATORS OF} ECONOMIC DEVELOPMENT

Interest rate is a key feature of money value in an economy. That is why in every country 6 there is a "benchmark interest rate", which is set by by the main regulator of monetary policy. In this case, by setting the benchmark interest rates, the regulator evaluates the available information about the state of the economy as a whole, makes a forecast about the expected pace and direction of the development of the economic system, as a rule, in the medium-term period. Modifying the benchmark interest rate, the regulator informs the markets about the would-be changes in the economic situation. Following the benchmark interest rate, all interest rates in the economy are adjusted one by one.

There are some other indicators of the financial market that allow evaluating possible development of the economy through the forecasting interest rates. One of the instruments is bond interest rates and their expected yields. Bonds are a widely used "player" on the stock market and they play a crucial role in determining future interest rates. At the same time, it is worthwhile singling out government bonds, the estimated risk of which is minimal among all the bonds traded on the market.

There are various methods of forecasting, based on bonds interest rates. One of the most frequently used methods in practice is the construction of the zero coupon yield curve (hereafter ZCYC).

Besides interest rates, the indicator of the economy situation is the money supply. There are several monetary aggregates (M0, M1, M2, M3, M4), which differ in the degree of liquidity of the money types included in them. According to this indicator dynamics, one can assess the state of the economy in general. According to Fisher's formula, the money supply (the amount of money) is inversely proportional to their value.

\section{THEORETICAL BASIS FOR THE CONSTRUCTION OF THE ZERO-COUPON YIELD CURVE}

As a debt instrument, each bond has a certain maturity date, circulation period and yield, which the issuer promises to the holder of the security. In addition, it is possible to evaluate all these parameters at any moment during the whole period of the security circulation. The possibility of evaluation enables the construction of a curve that bring into correlation the period of circulation with the expected yield.

Zero-coupon yield is applied to bonds for which the issuer does not pay cash coupons, and the yield is the interest rate that should be used as the discount rate when adjusting the face value of the bond to its offer price.

On some markets and for some periods, the situation may occur when there is no instrument with zero-coupon: there were not their placements or there is an analogue on the market with coupon yield. In such case, it is possible to determine "theoretical" coupon yield that correlates to yields of coupon financial instruments.

One of the methods of constructing ZCYC is bootstrapping. Bootstrapping is a process of constructing a "theoretical" yield curve while calculating the yield of a zerocoupon financial instrument for subsequent longer maturities, based on the interest rates of shorter-term securities. In the process of calculating, based on this method, zero-coupon 
interest rate structures are formed as a result of a combination of real coupon instruments in such a way that all cash flows except for the first and last period are mutually redeemed.

\section{ZERO-COUPON YIELD CURVE AS AN INDICATOR OF ECONOMIC DEVELOPMENT}

\section{A. Specific dynamics of the benchmark interest rate in the USA}

In the USA, the benchmark interest rate is set by the Federal Reserve System (hereinafter Fed). The Fed evaluates the economy state and after that makes a decision about modifying/maintaining the interest rate. The whole world keeps close track of Fed's decisions that affect stock markets.

For the United States of America, the financial crisis had extremely tangible effects (it emerged there); after it, the economy had to recover for a long time and become accustomed to new realities. That is why the Fed modified the interest rate in the late 2008s, lowering the benchmark interest rate to its minimum level and kept it unchanged until 2015 (i.e. 7 years).

TABLE I. DYNAMICS OF THE FED RATE

\begin{tabular}{|c|c|}
\hline Date of change & $\begin{array}{c}\text { New interest rate } \\
(\boldsymbol{\%})\end{array}$ \\
\hline $12 / 16 / 2008$ & $0-0.25$. \\
\hline $12 / 16 / 2015$ & $0.25-0.50$. \\
\hline $12 / 14 / 2016$ & $0.50-0.75$. \\
\hline $3 / 15 / 2017$ & $0.75-1$. \\
\hline
\end{tabular}

\section{B. Specific dynamics of the benchmark interest rate in Russia}

Before March 2013, the benchmark interest rate was the refinancing rate (since September 2012, it has been at the level of $8.25 \%$ ). In March 2013, the benchmark interest rate was the key Central Bank rate or the REPO rate (at this rate, the CB carries out REPO transactions with commercial banks). Initially, the refinancing interest rate level and the key one were different, but on January 1, 2016, they were equated to the level of the CB key rate.

The dynamics of the key rate was the following:

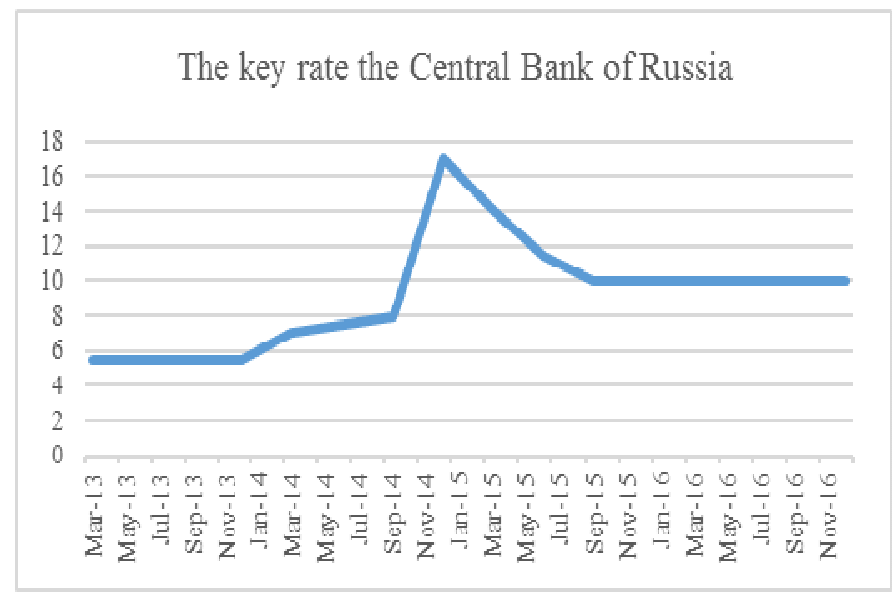

Fig. 1. The key rate of the Central Bank of Russia

For a long time (since 2013), the rate was kept unchanged, which indicated the normal state of the Russian economy. In 2014, the rate began to rise - a political situation worsened (the Crimea became a part of the Russian Federation), which was triggered by the reaction from the United States, the European Union member states and other countries in the form of imposing economic sanctions on Russia as a response to Russia's reaction. All these events affected the Russian economy and, as a result, it led to the sharp depreciation of the Russian ruble and significant fluctuation in its exchange rate the $\mathrm{CB}$ made a decision to allow the ruble to float and raised the key rate to $17 \%$. This way the $\mathrm{CB}$ managed to lower the foreign exchange rate, but Russia has not completely recovered from the currency crisis - by September 2015, the key rate decreased from $17 \%$ to $10 \%$, but the level is still higher than is was before the crisis.

\section{Yield curve in the USA}

In the United States, the yield curve of the Treasuries is the key factor for any domestic interest rates. Every day the Treasury Department of the US publishes the information about the yield curve on its official site on the Internet. For its construction, a cubic spline model is used. Besides the information about the yield curve, they also publish the data on

- T-bill rate;

- Yield curve for actual rates;

- Yield curve for high quality corporate bonds

- Other information.

At the end of the first quarter, the yield curve of corporate and Treasury bonds in the US was as follows: 


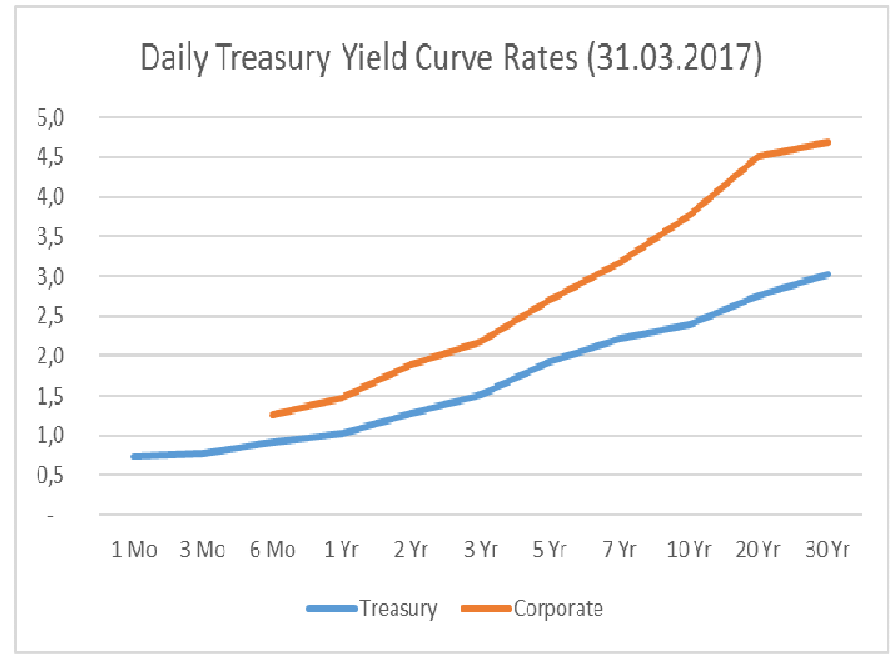

Fig. 2. Yield curve in the USA (3/31/2017)

Interest rates are steadily increasing along with the growth of the of their circulation terms. The shape of slope signals a normal state of the economy with a trend to increase. It is worth noting that Treasury bonds, as a risk-free asset, set the level of interest rates on the market. Even high-quality corporate bonds have a certain interest (risk) premium. At the same time, as the term of circulation rises - the spread between corporate and government bonds increases. This spread dynamics can be a forecasting indicator of the economic development (it is necessary to monitor the changes in the spread in their dynamics).

\section{Curve of zero-coupon yield in Russia}

Russia also uses the government bonds rate as an instrument to form the level of interest rates on the market. Before June 1, 2016, the Central Bank published the information about T-bills and federal bonds, in which it demonstrated the dynamics of long-term, medium-term and short-term bonds rates.

Starting from July 1, 2016, the Central Bank jointly with the Moscow International Currency Exchange (hereinafter referred to as the MICEX) has published a yield curve based on the the Nelson-Siegel model (the calculation methodology was updated). The curve is constructed based on T-billsfederal bonds market rates; the data are updated every day. The curve comprises the short term $(0.25-1$ year), the medium term (1-5 years) and the long term (7-30 years).

At the end of the first quarter of 2017, ZCYC was presented as follows:

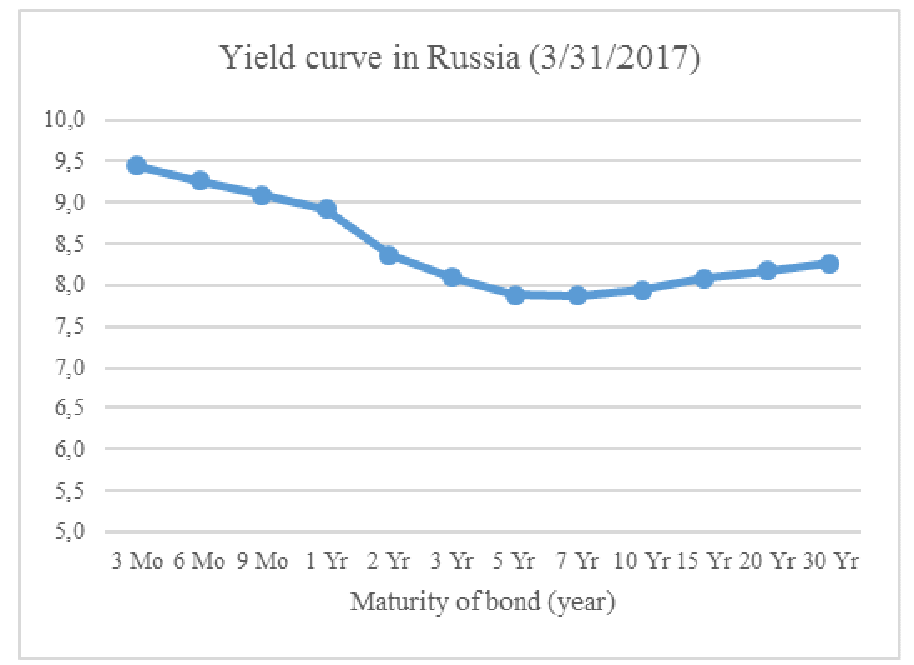

Fig. 3. Yield curve in Russia (3/31/2017)

The curve has an inversion slope, where the maximum interest rate is for a period of 0.25 years and is equal to $9.5 \%$. Further on, there is a gradual decline and for a period of 1 year, the rate is just $9 \%$. For the period longer than 1 year, the interest rate declined even sharper and reached its minimum for the term of 5-7 years (about 7.9\%). After 7-year term, there is a slight rise and the rates go smoothly to $8.3 \%$ for a term of 30 years.

One should remember that bonds yields reflect the riskiness of a bond, which is influenced by various factors. In this case, the authors consider securities of one issuer, which circulate on the same market. In this case, the main factor influencing the structure of bonds interest rates is their maturity.

This ZCYC is constructed based on T-bills interest rates and serves as an indicator of general economic situation. Therefore, the observed slope of the curve indicates certain economic difficulties. But one should take into account that the short-term part of ZCYC (0.25-1 year) is closely related to the key rate and is close to it in value: $3 / 26 / 2017$, the CB set a key rate of $9.75 \%$, which before that was $10 \%$. It turns out that the long-term bonds rates are in the range from $7.9 \%$ to $8.4 \%$. Such dynamics of ZCYC rates is the evidence that the economy is gradually recovering from the crisis, but one should not expect significant growth rates.

In contrast, let us compare $\mathrm{ZCYC}$ in other economic situation:

- The end of the 1 st quarter of 2015 - the crisis period with the key rate is higher than normal;

- $\quad$ The end of the 1st quarter, 2012 - the period, when Russian economy recovered from 2008-2009 financial crisis and functioned normally: 


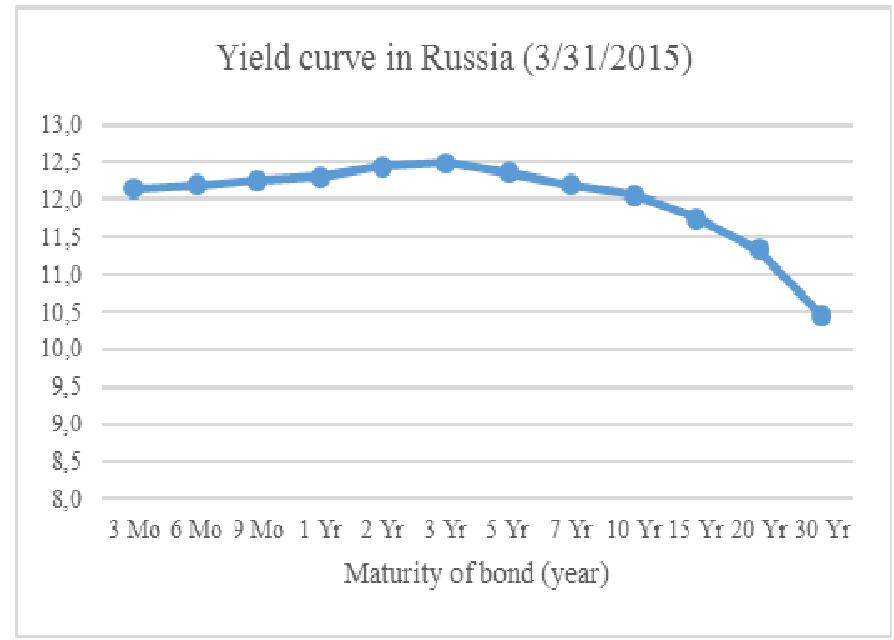

Fig. 4. Yield curve in Russia (3/31/2015)

Rates on the bond with a maturity of 0.25 to 3 years are in the range of $12-12.5 \%$ with a very narrow spread. Then one witnesses the contraction in rates; the process becomes faster as long as the maturity period is getting longer. This slope signals the serious difficulties in the economy, which can be overcome only in the long run.

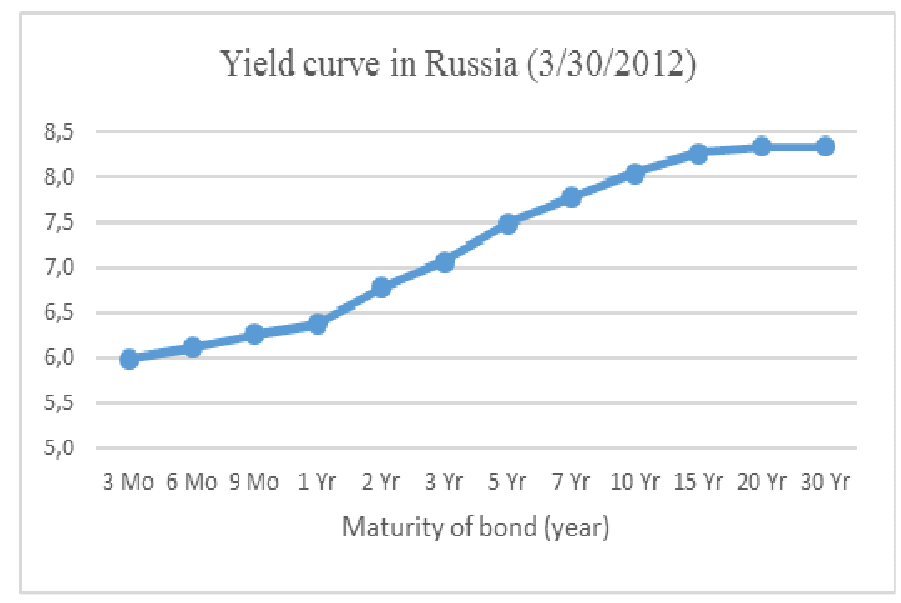

Fig. 5. Yield curve in Russia (3/30/2012)

At the end of the 1st quarter, 2012, the slope in ZCYC in Russia was similar to ZCYC slope in the USA, 1st quarter, 2017. Rates are gradually increasing along with their maturities: from $6 \%$ for the term of 0.25 to $6.5 \%$ for the term of 1 year, and then faster up to the term of 15 years, after which the rates remain stable.

In general, the shape of the curve indicates a normal economic state; the fact that for the terms of 15-30 years, the level of interest rates does not change is a little embarrassing.

\section{E. The bonds rates dynamics as a forecasting instrument}

While operating with ZCYC, the focus should be placed not only on the curve slope, but also on the time dynamics of the rates. In doing so, one can consider the rates dynamics, comparing short-term bonds with the longer ones, and evaluate the spread level. The expectation of various economic events has different effects on the bonds rates with different maturities, which means that the spread changes. The spread is perceived by the market as a signal to act - in technical analysis a "monetary filter" is used - this is the spread between the rates on bonds for 3 and 5 years. Usually it is evaluated weekly and makes an assumption about the expected changes in the market, based on its dynamics:

- $\quad$ if the spread decreases over time (now lower than 30 weeks ago), rates have a favorable downward trend, and the stock market reacts with a tendency to grow;

- if the spread increases over time, rates have a unfavorable upward trend, and the stock market reacts with a tendency to decline;

The following charts present the period from March 2012 to March 2017 (5 full years), reflecting:

- The dynamics of bonds interest rates depending on their maturities with the use of maturity terms of $1,3,10$ and 30 years.

- Dynamics of spreads between 3- and 1-year bonds (medium and short terms), between 5-year and 3-year bonds ("monetary filter"), between 30-year and 5-year bonds (the most long-term bond and medium-term one):

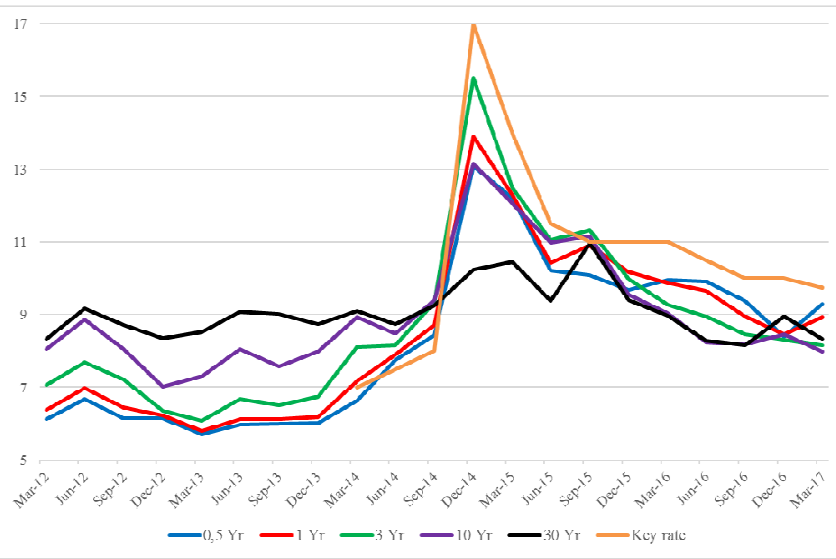

Fig. 6. The dynamics of bonds interest rates depending on their maturities

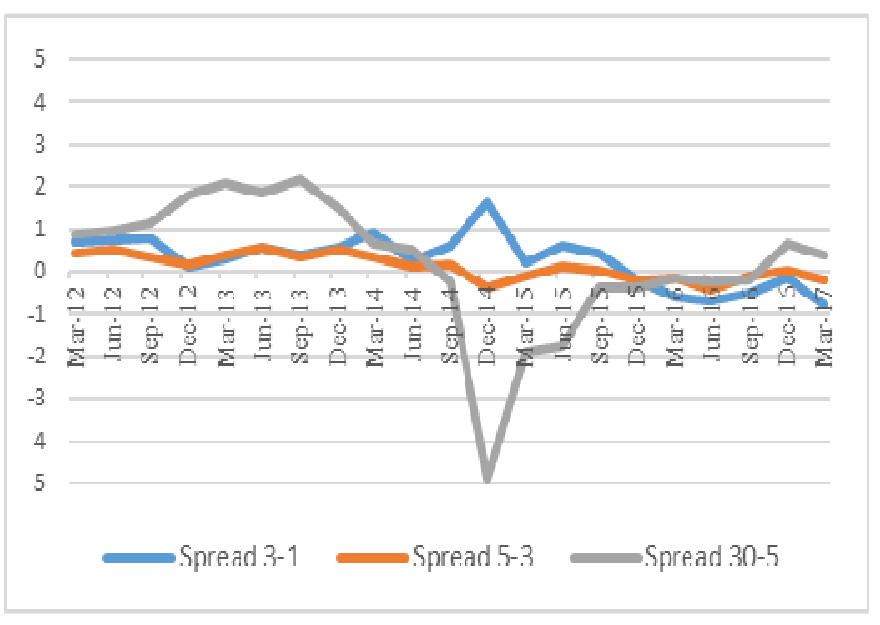

Fig. 7. The dynamics of spreads between interest rates of bonds 
Interest rates were quite variable in the period under review. At the same time, spreads between bonds of different maturities fluctuated significantly. In the period under review, the dynamics of the monitored indicators gives the following signals to the market:

- The sharp increase in all rates (excluding 30-year bonds) in 2014 indicated a negative change in the economic situation. The dramatic surge in December 2014, which occurred at the peak of the currency crisis in Russia under conditions of political tension, was quite "expected" result of the emerging trend. This surge in rates was influenced by the results of an emergency night meeting of the Central Bank on December 15, 2014, when the level of the key rate was raised from $10.5 \%$ to $17 \%$ (this was the 3rd rate increase in December 2014).

- If in 2014, 6-month and 1-year rates supported the dynamics of the key rate, then the 3-year bonds rates began their gradual growth in March 2013 and 10-year bonds rates in December 2012. The dynamics of changes in 3-year and 10year rates did not indicate a crisis but did not prevent the rise in interest rates in the economy.

- In addition to that, the analysis of bonds rates with maturity of 30 years was clearly signaling that the crisis has a certain speculative component - the rates increased from about $8.8 \%$ to $11 \%$. The maximum level of rates was observed in September 2015 - relative to other rates, the delay was about 9 months (which is too much for similar economic conditions).

- 2015 was difficult for forecast. The economy was in a state of crisis, there was a clear decline, which was reflected in the indicators. But the rates dynamics indicates that it was in 2015, when the peak of the crisis occurred. Starting from March 2016, the rates did not exceed 10\% (which is lower than the key one) and continued to decline. Heretofore, the risk that is taken into account at the key rate (short term ZCYC) exceeds the expected growth (long term ZCYC). But the ZCYC gradually gets even and returns to the normal shape of the curve. Considering the fact that the Central Bank in May again lowered the key rate, one can say that this indicates positive changes in the economy. Taking into account the latest news, one can make an assumption that by the end of 2017, the ZCYC will "level out", which will indicate a "recovery" of the economy - so that Russia will almost completely recover from the crisis. But the expected economic growth in the post-crisis period will be extremely restrained.

- Particular attention should be paid to the "rebound" of all rates (except for 10-year bonds) in September 2015. Since the beginning of the currency crisis in Russia, this was the only time when the rates of ZCYC and the key rate converged in their values. That was the market response to the active phase of Russia's military operation in Syria and the increased political instability.

- It can be seen that the ZCYC rates since September 2015 have been slightly ahead of the key rate. Therefore, the 1 -year bond rate is 1-2 quarters ahead of the key rate. Based on ZCYC dynamics, one can expect a further gradual decrease in the benchmark interest rate.
Spreads between bonds of different maturities amplify the dynamics of the rates:

- $\quad$ The steep "peak" in the spread between the 30-year and 5-year rates serves as a good characteristic of the state of the economy and reflects the mood of panic in the population.

- 3-year bonds rose most after the key rate was modified. The spread between 3-year and 1-year securities is the only indicator, which was increased in December 2014. After that, it returned to the state more relevant to the real situation: when longer-term rate is lower than the shorter-one. It is worth studying the influence of the benchmark interest rate on 3-year bonds rate.

- From September 2015 to September 2016 - the spread between 30-year and 3-year assets gradually approached 0, but was still in the negative zone - the indicator signals that the economy took a considerable period after the upheavals and only by the end of 2016 it could be said that the main consequences of the crisis had been left behind, so longterm growth was expected (the first signs of the economy recovery).

- The monetary filter (the spread between 5-year and 3year bonds) in dynamics shows the state of the Russian economy of that period: in 2012-2013 - a small economic growth (spread less than $0.5 \%$ ), in 2014 - the total tension "lowered" the indicator to $0 \%$ by June (six months ahead of time). In December 2014, it plunged into the negative zone (the open phase of the crisis), from which it could not get out until the end of 2016 - in the medium term, the economy was not yet ready to grow (only in the long run).

The curve of zero-coupon yield and dynamics of its rates have profound information concerning the economic state of the country. The dynamics of these indicators has a forecasting ability - for example, a monetary filter (a spread between 3-year and 5-year bonds) depicts the economic situation. And in 2012-2016, the development was 1-2 quarters ahead. Monitoring the indicators under review is useful for determining the possible further development of the economic situation.

\section{SPECIFICITY OF MONEY SUPPLY DYNAMICS IN RUSSIA}

Money supply is an indicator which is often considered as a forecasting one; the changes in this indicator demonstrate the economic state of the country. There are several monetary aggregates (depending on the liquidity of the funds in question), but in practice the money aggregates M2 ("money supply in the national definition" - as the CB defines it) is more often used.

First, let us look at the way the amount of money in the economy was changing relative to the same month a year earlier: 


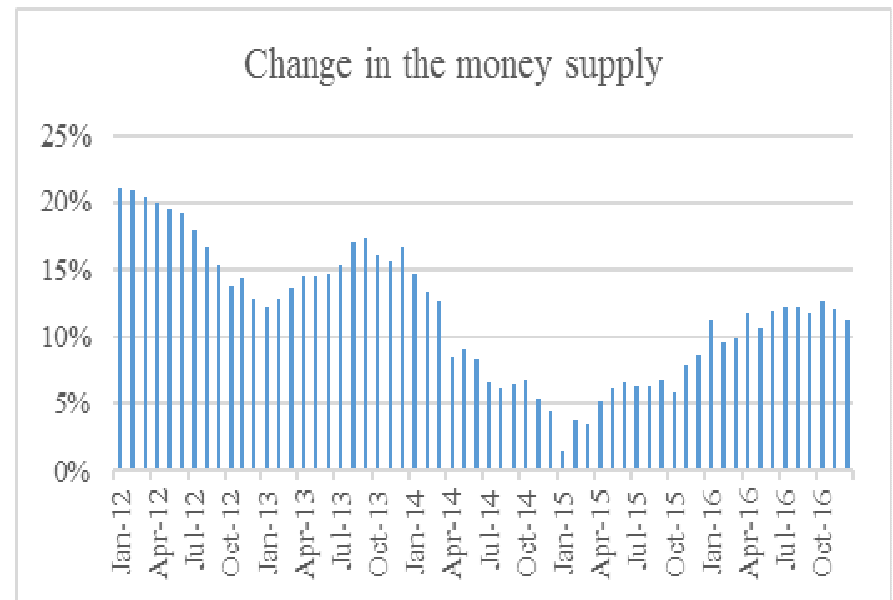

Fig. 8. The change in the money supply relative to the same month of the previous year

The graph shows that the growth rate gradually declined in 2012 - 2014. The minimum values fell on the peak of the currency crisis (late 2014 - early 2017), when the actions of the Central Bank made money expensive and significantly reduced their availability and liquidity. In general, the dynamics of changes before the crisis signaled that economic growth was gradually declining. In 2015 and 2016, growth rates were gaining momentum, which signaled a gradual recovery from the crisis. We can say that the dynamics of the indicator confirms the dynamics of the benchmark interest rate and gives similar signals about the development of the economy.

The M2 monetary aggregate is widely used as a forecasting indicator. For example, in the US, there is a nongovernmental organization The Conference Board [15], which publishes the Leading Economic Index once a month. This index is aimed at predicting the dynamics of the country's economy ahead of 3-6 months. The Index comprises 10 different macroeconomic indicators, including the indicator of monetary aggregate M2. But, in this case the monetary base is cleared out of inflation.

The graph below depicts the change in the money supply in Russia, measured in December 2011 prices - the actual volume was deflated by the inflation rate (the monthly inflation data published by the Central Bank was used). Here we have the following dynamics:

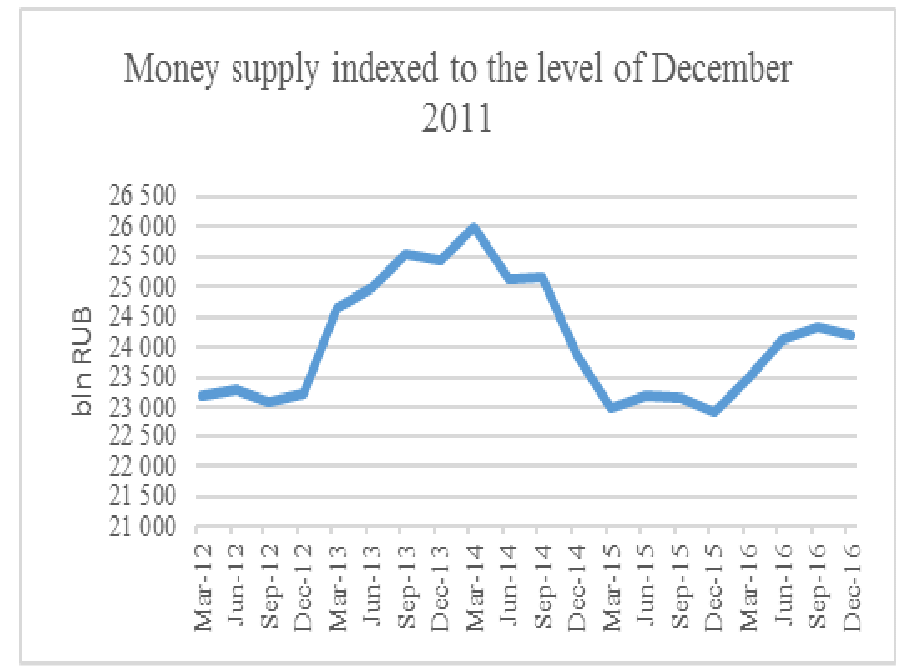

Fig. 9. The money supply indexed to the level of December 2011

Throughout 2012, the indexed money supply was stable with minimal changes. After that, the authors witnessed a rapid growth with a peak in March 2014, which was replaced by a sharp reduction and "bottom" from March to December 2015. In 2016, the money supply began to slightly "revive" the growth was seen in June 2016, after which there were small fluctuations - so far, the economy cannot reach once again the level of 2014 of 25 trillion rubles.

Indexed money supply also reflects the state of the economy, but during the crisis - a bit late:

- $\quad$ The key rate reached its maximum in December 2014 - the M2 monetary aggregate reached its lowest level in March 2015 (the M2 cycle could have affected the peak in December before the New Year holidays);

- the key rate started decreasing in 2015 - the money supply increased in 2016 (the CB conducted the the policy of "targeted inflation" - the inflation was viewed as one of the key economic risks).

The dynamics of money supply contains a lot of information concerning the current economic state and gives clear signals about possible changes in the economy. Therefore, it is worth keeping monitoring the changes in these indicators after the crisis.

\section{THE CORRELATION AMONG SEPARATE PARTS OF THE CURVE OF ZERO-COUPON YIELD WITH THE BENCHMARK INTEREST RATE}

In addition to the fact that the benchmark rate in the current situation follows the rates of $\mathrm{ZCYC}$, one can cite the correlation matrix of the benchmark interest rate and the data from the curve for the period March 2014 - March 2017:

The matrix demonstrates that between rates, there is a close correlation, which goes down when the maturity term exceeds 10 years. 
TABLE II. TABLE STYLES

\begin{tabular}{|c|c|}
\hline $\begin{array}{c}\text { Maturity of } \\
\text { bond }\end{array}$ & $\begin{array}{c}\text { Correlation with the } \\
\text { benchmark interest } \\
\text { rate }\end{array}$ \\
\hline 0.25 & 0.94 \\
\hline 0.50 & 0.97 \\
\hline 0.75 & 0.97 \\
\hline 1 & 0.97 \\
\hline 2 & 0.93 \\
\hline 3 & 0.90 \\
\hline 5 & 0.87 \\
\hline 7 & 0.84 \\
\hline 10 & 0.80 \\
\hline 15 & 0.74 \\
\hline 20 & 0.68 \\
\hline 30 & 0.55 \\
\hline & \\
\hline 5 & \\
\hline
\end{tabular}

VI. CONCLUSION

The indicative properties of the zero-coupon yield curve (ZCYC), which correlate with the monetary policy and the emerging economic conjuncture, are considered in the works by A. Estrella and F. Mishkin (1995) [6], A. Estrella, M. Trubin (2006) [7], in which the econometric model was constructed on the basis on the economic indicators. The authors concluded that ZCYC possess reliable forecasting properties and they should be applied to the analysis of the economic situation. In Russia such work on the assessment of bond rates was conducted by V.A. Lapshin, V.Y. Kaushansky, M.Z. Kurbangaleev [11], O.A. Avdeeva, A.A. Tsyplakov [12], A.V. Radionova, A.Y. Arshavsky [13] and T.M. Militskova [14].

In Russian E. Fedorova and E. Lukasevich [1] in the process of research defined the crisis indicators (based on the monetary policy indicators), resulting from statistical LRtesting and using mathematical models with Markovsky switches. The authors proposed considering 4 financial condition indices (FCI), which showed good results in application to the Russian economy.

In his book on technical analysis, J. Appel [2] gives an example of using a "monetary filter" as a forecasting instrument, which allows him to increase the profitability of his investments.

Under the conditions of the Russian economy, Belyanova E.V. and Nikolayenko S.A. [4] selected 17 indicators (including the "cleared" money supply, a set of indicators that are quite similar to indicators used by the Conference Board). Further, the authors analyzed the pre-crisis dynamics of the selected indicators and as a result found that they were all leaders in relation to the 2008 crisis.

K.V. Lapin [3], D.R. Belousov, E.A. Abramova, A.Y. Apokin, K.V. Mikhaylenko, E.A. Penukhina, A.S. Frolov [8],
A.Y. Apokin, D.R. Belousov [9], N.V. Akindinova, M.V. Petronevich [10] conducted an assessment of the economic situation in Russia through the construction of models. The main task is to search for indicators that would signal the onset of a crisis situation and its overcoming.

The macroeconomic indicators used in this article are published on the website of the Central Bank of the Russian Federation [16] and the US Treasury [17].

\section{Acknowledgment}

The publication was financially supported by the Ministry of Education and Science of the Russian Federation (Agreement № 02.A03.21.0008).

\section{References}

[1] I.Ya. Lukasiewicz, E.A. Fedorova, Forecasting of financial crises: methods, models, indicators, M: INFRA-M, 2015.

[2] J. Appel, Technical analysis. Effective tools for the active investor, St. Petersburg publishing house, 2007.

[3] K.V. Lapin, "The role of the bond model in forecasting the interest rate vector", Izvestiya URGEU, No 63-1, pp. 168-169, 2008.

[4] E.V. Belyanova, S.A. Nikolayenko, "A business cycle in Russia in 1998-2008: origin of internal mechanisms of cyclic development or import of world shocks?", Economic magazine HSE, No. 1 (16), pp. 31$57,2012$.

[5] N.B. Boldyreva, A.A. Parfyonov, "System of indicators of the crisis phenomena in the Russian stock market: dynamics and the advancing properties", Izvestiya URGEU, No. 3-4 (47-48), pp. 52-60, 2013.

[6] A. Estrella, F.S. Mishkin, "Predicting US Recessions: Financial Variables as Leading Indicators", Federal Reserve Bank of New York, No. 9609, pp. 1-36, 1995.

[7] A. Estrella, M.R. Trubin, "The Yield Curve as a Leading Indicator: Some Practical Issues", Federal Reserve Bank of New York, Current Issues in Economics and Finance,. Vol. 12, No. 5., pp. 1-7, 2006.

[8] D.R. Belousov, E.A. Abramova, A.Y. Apokin, K.V. Mikhaylenko, E.A. Penukhina, A.S. Frolov, "Future of Russia: macroeconomic scenarios in a global context", Forsythe, No. 2., pp. 6-25, 2013.

[9] A.Y. Apokin, D.R. Belousov, "Scenarios of development of the world and Russian economy as basis for scientific and technological forecasting", Forsythe, No. 3, pp. 12-29, 2009.

[10] N.V. Akindinova, M.V. Petronevich, "Than will end crisis? Mediumterm scenarios of development of the world and Russian economy", Forsythe, No. 4, pp. 22-35, 2009.

[11] V.A. Lapshin, V.Y. Kaushansky, M.Z. Kurbangaleev, "Valuation of curve non-coupon profitability in the Russian bond market", the Economic magazine HSE, No. 1, pp. 9-29, 2015.

[12] O.A. Avdeeva, A.A. Tsyplakov, "Method of adaptive estimation of urgent structure of interest rates", Economic magazine HSE, No. 4, pp. 609-639, 2015.

[13] A.V. Rodionova, A.Y. Arshavsky, "The Empirical analysis of formation of profitability in the Russian market of the state securities", the Economic magazine HSE, No. 3, pp. 285-317, 2012.

[14] T.M. Militskova, "Influence of specific factors on spreads of profitability of corporate bonds", Corporate finance, No. 2 (26), pp. 4666, 2013.

[15] The Conference Board - https://www.conference-board.org/ ;

[16] Central Bank of the Russian Federation - http://www.cbr.ru ;

[17] U.S. Department of the Treasury https://www.treasury.gov/Pages/default.aspx 